\title{
Consumo de pescado: \\ los beneficios superan los potenciales riesgos
}

\author{
A Fish consumption: its benefits outweigh potential risks
}

Mozaffarian D y col. JAMA 2006; 296:1885-1899

\section{Objetivo}

Revisar la evidencia científica sobre beneficios y riesgos de consumo de pescado sobre la salud.

\section{Fuente y Selección de Datos}

MEDLINE, informes del gobierno, revisiones sistemáticas y meta-análisis, revisiones manuales de las referencias y contactos directos con investigadores para identificar publicaciones hasta 2006 relacionadas con: 1) ingesta de pescado o su aceite (AP) y riesgo cardiovascular (CV). 2) efectos del metilmercurio (MM) y el AP sobre el desarrollo neurológico temprano, 3) riesgos cardiovasculares y neurológicos en adultos asociados al consumo de metilmercurio, y 4) riesgos de las dioxinas y los policlorados bifenilos (PCB) presentes en el pescado. La búsqueda se focalizó en estudios aleatorizados y estudios prospectivos grandes. Cuando fue posible, se realizaron metaanálisis ${ }^{*}$ para caracterizar los riesgos y beneficios de manera más precisa.

\section{Resultados principales}

El consumo de una o dos porciones de pescado por semana (especialmente aquellos con un elevado contenido de ácidos grasos Omega 3) disminuyó el riesgo de mortalidad CV un 36\%
(IC95\%: 20 a 50) y la mortalidad total un 17\% (IC95\%: 0 a 32). El ácido docosahexanoico mostró un efecto beneficioso sobre el desarrollo neurológico temprano, mientras que el metilmercurio resultó perjudicial aún en niveles bajos de exposición. Si bien todavía no se determinaron los efectos del metilmercurio sobre los adultos, disminuiría los beneficios cardiovasculares del pescado.

El contenido de dioxinas y bifenilos policlorinados del pescado es bajo y similar al de otros alimentos, no superando sus potenciales efectos nocivos a los beneficios reconocidos de su ingesta.

\section{Conclusiones}

Los beneficios del consumo de una a dos porciones semanales de pescado superan a los potenciales riesgos. Las mujeres embarazadas o en período de lactancia y los niños deben evitar las especies de pescado con elevado contenido en metilmercurio, pero también en ellos, los beneficios superan a los riesgos.

Palabras clave: pescado, metilmercurio, aceites de pescado, riesgo cardiovascular. Key words: fish, metyl-mercurio, fish oil, cardiovascular risk. Fuente de financiamiento: National Heart, Lung and Blood Institute.

\section{Comentario}

Una sólida evidencia avala el beneficio $\mathrm{CV}^{1}$ del consumo de pescado y de cápsulas de AP. Los efectos cardioprotectores se relacionan con el contenido en ácidos grasos omega 3 y su acción anti-arrítmica, el mejoramiento de la función endotelial, la inhibición de la formación de la placa de ateroma y sus propiedades antitrombóticas y anti-inflamatorias; siendo los pescados de mar de aguas profundas (caballa, sardinas, salmón, arenque) los que poseen mayor cantidad de acidos omega 3 (eicosapentanoico y docosahexanoico).

La Asociación Americana del Corazón recomienda un consumo mínimo de dos porciones $(200$ a $400 \mathrm{~g}$ ) de pescados grasos por semana, mientras que el Programa Nacional de Educación sobre el Colesterol de EE.UU. (NCEP-ATP III) menciona la importancia de incluir este alimento para reducir el riesgo de enfermedad $\mathrm{CV}^{2}$.

Recientemente se ha alertado sobre el potencial riesgo de las dioxinas, el MM y otros contaminantes presentes en el pescado. El MM es absorbido por los peces a través del agua, depositándose en sus tejidos. Cuanto más grande y viejo es el pez, mayor cantidad de MM posee, siendo las especies con alto contenido el tiburón, el pez espada, la caballa gigante y algunos tipos de atún, pero nó las que se consumen habitualmente en nuestra región. Aún no están claros sus efectos en adultos, pero sí se ha observado que el metilmercurio puede resultar perjudicial para el desarrollo neurológico temprano. Por eso, la Agencia de Protección Ambiental y la de Drogas y Medicamentos de EEUU han aconsejado que las embarazadas, las mujeres en período de lactancia y los niños consuman dos porciones semanales de pescado con bajo contenido de mercurio y eviten las especies con alto contenido de este contaminante. Para los adultos que consumen más de cinco a seis porciones semanales de pescado, advierten que limiten el de dichas especies.

\section{Conclusiones del comentador}

La evidencia existente avala que los beneficios del pescado para la salud superan ampliamente sus riesgos en la mayoría de la población.

Ver glosario*

Lic. Alejandra Delfante. [ Servicio de Alimentación, Hospital Italiano de Buenos Aires. ]

Delfante A. Consumo de pescado: los beneficios superan los potenciales riesgos. Evid. actual. práct. ambul; 10(5): 136, Sept-Oct.2007. Comentado de: Mozaffarian D, Rimm EB. Fish intake, contaminants, and human health: evaluating the risks and the benefits. JAMA. 2006 Oct 18 ; 296 (15):1885-99. PMID: 17047219

Referencias

1. Kromhout D, Bosschieter EB, de Lezenne Coulander C. The inverse relation between fish consumption and 20-year mortality from coronary heart disease. $\mathrm{N}$ Engl $\mathrm{J}$ Med. 1985; 312:1205-1209.

2. Diet and Lifestyle Recommendations Revision 2006: A Scientific Statement From the American Heart Association Committee. Circulation 2006; 114:82-96. 